Copyright (C) 2015 by Academic Publishing House Researcher

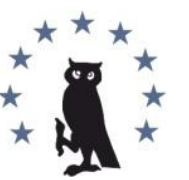

Published in the Russian Federation

European Researcher

Has been issued since 2010.

ISSN 2219-8229

E-ISSN 2224-0136

Vol. 95, Is. 6, pp. 451-456, 2015

DOI: 10.13187/er.2015.95.451

www.erjournal.ru

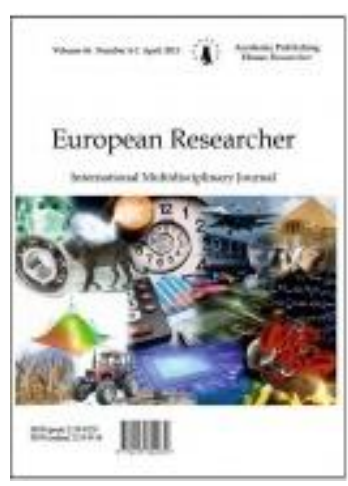

Philological Sciences

Филологические науки

UDC 81

\title{
The Onomastic Phraseological Units in the Works of I.V. Goethe (Compiled By Authors «German Onomastic Phraseological Dictionary»)
}

\author{
Manana Napireli
}

Telavi State University, Georgia

\begin{abstract}
In the given work we've got interested in one of the branch of linguistics, onomastics, actually, onomastical phraseology. The research of the onomastical field concerns the proper nouns. This trend of linguistics is very actual in our modern words and attracts much attention. Although, the research of proper nouns comes from the ancient time. The aim of our study is to find those quotes from the works of the greatest representative of German classical literature I.V. Goethe, which possess the proper nouns that became the phraseological units and expressions. The work of I.V. Goethe seems to be very interesting from the point of onomastical phraseology. We've revealed 12 onomastical expression; 8 in "Phaust" and 4 in defferent writings.
\end{abstract}

Keywords: onomastics, phraseology, winged words, citation.

\section{Введение}

Всеми признана роль фразеологии и ее место в том или ином языке. Как необычное языковое явление она вызывает собой большой интерес и для языковедов является предметом исследования. Опираясь на переносное значение составляющих компонентов, значение фразеологизмов в разных языках мотивируется по-разному. Выполнить дословные переводы фразеологизмов невозможно, необходимо найти и соответствующий в языке аналогичный эквивалент.

Под фразеологией подразумеваются прочно сложившиеся в том или ином языке выражения, своеобразное соединение слов.

\section{Обсуждение}

Согласно Такаишвили (1961: 5-6) вместе с отдельными словами и именами в языке выделяются прочные соединения слов, которые играют большую роль для показа разных явлений действительности. Язык владеет неисчислимым количеством готовых форм, которые кроме своего исходного значения имеют и переносный смысл. Именно здесь начинается фразеология, когда значения компонентов теряются, а слова перед нами встают уже в виде семантической единицы. Фразеологизмы выражают единую мысль, велика их 
эмоциональная сила и в подобных случаях они могут точно передать душевное состояние и настроение человека. На них возложена экспрессивная функция, благодаря им речь становится более многоцветной, гибкой и красочной.

Из всех творений языкового гения человека фразеология - наиболее сложное и самобытное явление. Фразеологический состав языка достаточно живо реагирует на развитие общества, он весьма специфичен в каждой эпохе, стране и у каждого народа.

Результатом образности языка является его экспрессивность. Мысль, высказанная фразеологизмом, намного сильнее, богаче и ярче, нежели переданная простыми словами.

Фразеологизм многоизмеряемая структура. Она понимается и чувствуется языковыми носителями и содержит эмоции, оценки, национальные образы, которые характерны для той или иной культуры.

„Die Phraseologie ist eine junge wissenschaftliche Teildisziplin. Fruher wurde sie als Teilgebiet der Lexikologie betrachtet. Der Grund dafur ist, dass die Phraseologismen eigentlich Einheiten des Wortschatzes (wie die Worter) sind, und darum wurden sie so untersucht und beschrieben“ (Burger, H. Buhofer, A. Sialm, A. 1982: 14).

Мы заинтересовались одной из важнейших отраслей языкознания - ономастикой, а именно ономастической фразеологией. Исследование ономастического поля связано с собственными именами. Данное направление языкознания в настоящее время весьма актуально и пользуется возрастающим вниманием. Хотя собственные имена изучаются и исследуются с давних времён.

Согласно Хорнаули (2003: 8) ономастика (греческое слово, обозначающее искусство присваивания имён) - область языкознания, изучающая собственные имена. Это наука, изучающая имена со всех сторон. Она по мере того, как занимается изучением географических названий и собственных имён сточки зрения их происхождения, развития, изменения, функций, языковых перемен и структуры, весьма занимательна и интересна.

„Onomastik („Namenswissenschaft“), beschäftigt sich mit der Bedeutung, Herkunft und Verbreitung von Namen“. (Naumann, H. 1986: 17)

„Ономастика, в свою очередь, - та часть лексики, которая тесно связана с потребностями общества и целиком обусловлена социально-историческими, социальноэкономическими и социокультурными факторами. Имя собственное - это один из "продуктов" человеческой культуры. Оно возникает в коллективе, из потребностей коллектива и отражает черты, значимые для коллектива, находящегося на определенной ступени исторического развития" (Суперанская, А.В. 1977: 5).

\section{Методы исследования}

Составленный нами словарь, содержит 485 ономастических фразеологических единиц. Он исследует происхождение ономастических фразеологизмов. Высказывания связаны с различной тематикой: 1) антропонимы - собственные имена людей; 2) имена литературных героев; 3) имена богов, библейские имена, мифологические имена; 4) имена святых; 5) топонимы - имена географических объектов и многие другие.

В данном труде предметом нашего исследования являются фразеологические единицы из литературных произведений, в состав которых входят собственные имена. В частности речь идёт о поиске в творчестве великого представителя немецкой классической литературы И.В. Гёте цитат, в составе которых имеются собственные имена, ставшие фразеологическими единицами и крылатыми фразами.

Нами было добыто 12 ономастических высказываний. Из них 8 встречаются в «Фаусте», а 4 - в таких произведениях как «Эгмонт», «Торквато Тассо», «Гец фон Берлихинген», «Ифигения в Тавриде».

Целью нашего исследования также было выяснение того, в каких условиях используется та или иная цитата.

1. wenn hinten, weit, in der Türkei, die Völker aufeinander schlagen

Dieses Zitat aus Goethes Drama Faust I charakterisiert den typischen Spiessbürger:

„Nichts Bessers weiss ich mir an Sonn- und Feiertagen

Als ein Gespräch von Krieg und Kriegsgeschrei,

Wenn hinten, weit, in der Türkei, 
Die Völker aufeinander schlagen“.

(I. W. Goethe, "Faust” I Teil, Vor dem Tor)

\section{Parnass}

Nach dem altgriechischen Dichter Homer ist der Parnass ein Berg in Phokis, an dessen Fusse Apollo, der Gott des Lichtes und der Musen, einen Tempel für sich errichten liess. Daher wird der Name Parnass in der Bedeutung „Sitz der Musen (der neun Göttinnen der Kunst) und Dichter und danach „alle Dichter einesVolkes“ gebraucht.

Ein anderer Aufenthalt der Musen soll Helikon, ein Berg in Böotien (Griechenland) gewesen sein.

Parnass besingr J. W. Goethe in seinem „Faust“.

„Mit rechten Leuten wird man was.

Komm, fasse meinen Zipfel!

Der Blocksberg, wie der deutsche Parnass,

Hat gar einen breiten Gipfel“.

(J. W. Goethe „Faust“ Der Walpurgisnachtstraum)

3. mein Leipzig lob ich mir!Es ist ein klein Paris und bildet seine Leute

Es ist ein Zitat aus der Tragödie „Faust“ (I. Teil) von J. W. Goethe.

Diese Worte über Leipzig lässt Goethe einen der lustigen Gesellen, die im Auerbachs Keller zechen, sagen.

„Frosch:

Wahrhaftig, du hast Recht! Mein Leipzig lob’ ich mir!

Es ist ein klein Paris, und bildet seine Leute".

(J. W. Goethe, ,Faust“, I. Teil, „Auerbachs Keller in Leipzig“). spricht.

Sie wurden zum Motto der Stadt und werden oft zitiert, wenn man über Leipzig schreibt oder

4. Heinrich! Mir grauts vor dir

Dieses Zitat stammt aus Goethes Tragödie Faust, 1. Teil. In der Kerkerszene widersteht Gretchen der Versuchung, mit Fausts und Mephistos Hilfe zu entfliehen und damit ihrer Hinrichtung zu entgehen. Sie will so ihre Schuld büssen und wendet sich von Faust mit den Worten $\mathrm{ab}$ :

Margarete:

Dein bin ich, Vater! Rette mich!

Ihr Engel! Ihr heiligen Scharen,

Lagert euch umher, mich zu bewahren!

Heinrich! Mir graut's vor dir.

(J. W. Goethe "Faust", 1. Teil, Kerker)

Diese Worte werden (auch abgewandelt mit anderen Namen) zitiert, wenn einem jemand drohend oder unheimlich erscheint, besonders auch, wenn einen jemand mit Verlockungen zur Teilnahme an seinem unheilvollen Vorhaben bewegen will.

\section{5. $\quad$ Hans Liederlich}

Das Zitat stammt aus Goethes „Faust“. Es verwendet man, wenn von einem gemeinen, ehrlosen Menschen die Rede ist.

MEPH.

Du sprichst ja wie Hans Liederlich,

Der begehrt jede liebe Blum' für sich,

Und dünkelt ihm, es wär' kein' Ehr'

Und Gunst, die nicht zu pflücken wär';

Geht aber doch nicht immer an.

\section{(Goethe "Faust", I Teil, Strasse)}

\section{Gretchenfrage}

„Entscheidende Frage stellen, jedoch mit einer ausweichenden Antwort rechnen". Ihren Ursprung hat diese Redewendung in Goethes Faust. Wohl erst im 20 Jh.wird diese Frage in übertragenem Sinn als „wichtige, schwierige, komplizierte Frage“, als „Gewissensfrage“ gebraucht“. MARGARETE.

Nun sag, wie hast du's mit der Religion?

Du bist ein herzlich guter Mann, 
Allein ich glaub', du hältst nicht viel davon.

FAUST.

Lass das, mein Kind! Du fühlst, ich bin dir gut;

Für meine Lieben liess' ich Leib und Blut,

Will niemand sein Gefühl und seine Kirche rauben.

(J. W. Goethe, „Faust“, I. Teil, Marthens Garten).

7. ein echter deutscher Mann mag keinen Franzen leiden, Doch ihre Weine trinkt er gut

Es ist ein Zitat aus der Tragödie „Faust“ (I. Teil) von J. W. Goethe. bestellt.

Die Worte sagt beim Zechen der lustige Geselle Brander, indem er sich Champagner Wein

BRANDER:

„Man kann nicht stets das Fremde meiden

Das Gute liegt uns oft so fern.

Ein echter deutscher Mann mag keinen Franzen leiden,

Doch ihre Weine trinkt er gern“.

(J. W. Goethe, „Faust“, I. Teil, „Auerbachs Keller in Leipzig“).

Den Ausspruch verwendet man heute, wenn man den deutschen Nationalismus (bzw. nationalistische Äusserungen) verspotten und brandmarken will.

8. Im Deutschen lügt man, wenn man höfflich ist

In der Szene im 2. Teil von Goethes „Faust“ trifft Mephisto, als Professor verkleidet, wieder auf den Schüler aus der Studierzimmerszene des 1. Teils. Dieser hat jetzt zum untersten akademischen Grad des Bakkalaureus promoviert. Ungehalten lässt er jetzt eine Schimpfkanonade auf Lehrer und universitären Lehrbetrieb los. Auf Mephistos Frage, ob er sich denn nicht seiner Grobheit bewusst sei, kommt die Rechtfertigung:

MEPHISTOPHELES:

Du weisst wohl nicht, mein Freund, wie grob du bist?

BACCALAUREUS:

Im Deutschen lügt man, wenn man höflich ist.

„J. W. Goethe „Faust“ (2Teil) „Hochgewölbtes, enges gotisches Zimmer“ 2. Akt)

Zitiert werden diese Worte heute auch dann, wenn man eine Äusserung zurückweisen will, die man nicht mehr als Zuvorkommenheit auffasst, sondern als übertriebene und deplatzierte Schmeichelei empfindet.

9. Das kommt mir spanisch vor

In dem Drama „Egmont“ von J. W. Goethe sagt der Titelheld (Egmont) zu Clärchen:

EGMONT: Bist du zufrieden? Ich versprach dir, einmal spanisch zu kommen.

Danach zitieren wir scherzhaft Das kommt mir spanisch vor, wenn wir etwas nicht verstehen oder komisch finden.

10. du siehst mich lächelnd an, Eleonore

Diesen Satz kann man jemandem gegenüber im Scherz zitieren, wenn man ihn eigentlich fragen will: „Was hast du? Was gibt es? Ist irgendetwas nicht in Ordnung?“ Es ist der Satz, mit dem das Schauspiel „Torquato Tasso“ von Goethe beginnt, und er steht dort in einer ganz ähnlichen Funktion. Die Prinzessin Leonore von Este spricht ihn zu ihrer Freundin Leonore Sanvitale.

PRINZESSIN

Du siehst mich lächelnd an, Eleonore,

Und siehst dich selber an und lächelst wieder.

Was hast du? Lass es eine Freundin wissen!“

(J. W. Goethe, Torquato Tasso, 1. Akt, 1. Auftritt)

11. stirb, Götz, du hast dich selbst überlebt

Götz ist der Hauptheld im J. W. Goethes Drama „Götz von Berlichingen“.Goethe verklärt Berlichingen zum Kämpfer gegen das Unrecht - in Wirklichkeit ist er ein erfolgreicher Raubunternehmer. Zum Verhängnis werden ihm erst die Bauernkriege. Als 1525 die rebellierenden Bauernarmeen Franken erreichen, fordern sie den beim Volk beliebten Berlichingen dazu auf, sie zu führen. Er lehnt zunächst ab. Götz wurde zum Tode verurteilt. Vor dem Tod sagt er: 
Ach dass ich Georgen noch einmal sähe, mich an seinem Blick wärmte! - Ihr seht zur Erden und weint - Er ist tot - Georg ist tot. - Stirb, Götz - Du hast dich selbst überlebt, die Edeln überlebt.

(Goethe "Götz von Berlichingen", Fünfter Akt, Gärtchen am Turm)

12. das Land der Griechen mit der Seele suchend

Im Anfangsmonolog des Schauspiels „Iphigenie auf Tauris“ von Goethe beklagt die Titelheldin ihr Schicksal, fern von ihrer Heimat Griechenland weilen zu müssen, festgehalten in einem Land, das ihr fremd geblieben ist.

„Denn ach mich trennt das Meer von den Geliebten,

Und an dem Ufer steh' ich lange Tage

Das Land der Griechen mit der Seele suchend (J. W. Goethe „Iphigenie auf Tauris“ 1. Aufzug, 1. Auftritt). Von ihrer Klage wurde die letzte Zeile „Das Land der Griechen mit der Seele suchend;““ zum geflügelten Wort. Sie wurde zu einer Art Formel, die häufig zitiert wurde (besonders als im 18. Jahrhundert das Interesse von der römischen auf die griechische Antike gelenkt wurde) und die auch heute noch zitiert wird, wenn es darum geht, das Interesse an der Kultur des griechischen Altertums zu benennen

\section{Выводы}

В виде заключения хочу отметить, чтотворчество И.В. Гёте оказалось весьма богатым ономастической фразеологией. В его творчестве мы нашли 12 ономастических единиц, из которых 8 былов «Фаусте», а остальные 4 - в других произведениях. Мы также ознакомились и с тем в каких случаях используется та или иная цитата и почему она стала крылатой.

\section{Примечания:}

1. А. Такаишвили (1961), Вопросы грузинской фразеологии, Тбилиси.

2. . Хорнаули (2003), Грузинская ономастика, Тбилиси.

3. BüchmanN, G. (1920), Geflügelte Worte: Der Zitatenschatz des deutschen Volkes gesammelt und erläutert von G Büchmann, Fortgesetzt von Walter Robert =tornow, Konrad Weidling und Eduard Ippel Sechsundzwanzigste Auflage neu bearbeitet von Bogdan Kriege Dritter, unveränderter Abdruck, BerlinInternet Archive geflgeltewortedo5bcgoog

4. Немецко-русский фразеологический словарь (1975), Составили Л.Э. Бинович и Н.Н. Гришин. Под редакцией д-ра Малиге-Клаппенбах и Агрикола. Издательство «Русский язык». Москва.

5. Суперанская. А.В. (1977) Ономастическая фразеология в лингвокультурологическом аспекте: на материале немецкого языка. Москва.

6. Шишкина, И.П.; Финкельштейн, Р.В. (1972) Крылатые слова, их происхождение и значение. Ленинград.

7. Burger, H. Buhofer, A. Sialm, A. (1982) Handbuch der Phraseologie. Berlin geflgeltewortedo5bcgoog

8. Duden, Band 11: (1998). Redewendungen und sprichwörtliche Redensarten: Wörterbuch der deutschen Idiomatik. Dudenverlag. Mannheim, Leipzig, Wien, Zürich. Zürich.

9. Duden (2003), Deutsches Universalwörterbuch. 5. Aufl. Mannheim, Leipzig, Wien,

10. Напирели M, (2014) немецкий ономастический фразеологический словарь, Тбилиси, издательство Универсал.

11. Naumann, H. (1986) Vornamen heute, Fragen und Antworten zur Vornamengebung. Leipzig: VEB Bibliographisches Institut Leipzig. 1986.

12. Goethe, J. W. (1986) Faust 1. Der Tragödie erster Teil. Philipp Reclam jun. Verlag GmbH

13. Johann Wolfgang von Goethe (1999) Werke Hamburger Ausgabe in 14 Bänden Deutscher Taschenbuch Verlag.

\section{References:}

1. A. Takaishvili (1961), Voprosy gruzinskoi frazeologii, Tbilisi.

2. G. Khornauli (2003), Gruzinskaya onomastika, Tbilisi. 
3. BüchmanN, G. (1920), Geflügelte Worte: Der Zitatenschatz des deutschen Volkes gesammelt und erläutert von G Büchmann, Fortgesetzt von Walter Robert =tornow, Konrad Weidling und Eduard Ippel Sechsundzwanzigste Auflage neu bearbeitet von Bogdan Kriege Dritter, unveränderter Abdruck, BerlinInternet Archive geflgeltewortedo5bcgoog

4. Nemetsko-russkii frazeologicheskii slovar' (1975), Sostavili L. E. Binovich i N.N. Grishin. Pod redaktsiei d-ra Malige-Klappenbakh i AGRIKOLA. Izdatel'stvo «Russkii yazyk». Moskva.

5. Superanskaya. A.V. (1977) Onomasticheskaya frazeologiya v lingvokul'turologicheskom aspekte: na materiale nemetskogo yazyka. Moskva. Leningrad.

6. Shishkina, I.P.; Finkel'shtein, R.V. (1972) Krylatye slova, ikh proiskhozhdenie i znachenie.

7. Burger, H. Buhofer, A. Sialm, A. (1982) Handbuch der Phraseologie. Berlin geflgeltewortedo5bcgoog

8. Duden, Band 11: (1998). Redewendungen und sprichwörtliche Redensarten: Wörterbuch der deutschen Idiomatik. Dudenverlag. Mannheim, Leipzig, Wien, Zürich.

9. Duden (2003), Deutsches Universalwörterbuch. 5. Aufl. Mannheim, Leipzig, Wien, Zürich.

10. Napireli M, (2014) nemetskii onomasticheskii frazeologicheskii slovar', Tbilisi, izdatel'stvo Universal.

11. Naumann, H. (1986) Vornamen heute, Fragen und Antworten zur Vornamengebung. Leipzig: VEB Bibliographisches Institut Leipzig. 1986.

12. Goethe, J. W. (1986) Faust 1. Der Tragödie erster Teil. Philipp Reclam jun. Verlag GmbH

13. Johann Wolfgang von Goethe (1999) Werke Hamburger Ausgabe in 14 Bänden Deutscher Taschenbuch Verlag.

УДК 81

Ономастические фразеологические единицы в произведениях И.В. Гёте
(по составленному нами «Немецкому ономастическому
фразеологическому словарю»)

Манана Напирели

Телавский государственный университет, Грузия

Аннотация. Мы заинтересовались одной из важнейших отраслей языкознания ономастикой; а именно - ономастической фразеологией. Изучение ономастического поля связывается с собственными именами. Это направление языкознания в настоящее время весьма актуально и пользуется большим интересом. Хотя исследование собственных имён берёт своё начало с давних времён.

Цель нашего исследования состоит в том, чтобы найти в творчестве великого представителя немецкой классической литературы И.В. Гёте те цитаты, в состав которых входят собственные имена, ставшие фразеологическими единицами и крылатыми фразами.

Творчество И.В. Гёте оказалось весьма богатой ономастической фразеологией. В его произведениях мы нашли 12 ономастических высказываний, из которых 8 - в «Фаусте»а остальные 4 в других произведениях.

Ключевые слова: Ономастика, фразеология, цитата, крылатые слова. 